\title{
Evaluation of Ankistrodesmus falcatus for Bicarbonate-Based Integrated Carbon Capture System (BICCAPS)
}

\author{
Arnel B. Beltran ${ }^{l, *}$, Daniel C. Gravador ${ }^{l}$, Bea Lutchi O. Ty ${ }^{l}$, Joceleen Michelle O. Wu ${ }^{l}$ \\ ${ }^{1}$ Chemical Engineering Department, De La Salle University - Manila, Manila, Philippines
}

\begin{abstract}
This study evaluates the performance of alkaliphilic microalgae Ankistrodesmus falcatus in the Bicarbonate-based Integrated Carbon Capture and Algae Production System (BICCAPS). The system utilized bicarbonate as carbon source for microalgae production. BICCAPS parameters such as $\mathrm{pH}$, algal biomass productivity and $\mathrm{CO}_{2}$ utilization (inorganic carbon conversion, $\mathrm{C}_{\mathrm{i}}$ ) were observed at different sodium bicarbonate $\left(\mathrm{NaHCO}_{3}\right)$ loading concentration and type of culture media. The highest productivity was observed at $10 \mathrm{~g} / \mathrm{L}$ of $\mathrm{NaHCO}_{3}$ loading in BRSP medium at $3.5539 \mathrm{mg} / \mathrm{L} /$ day. This value is $30 \%$ lower compared to the control experiment (continuously aerated bioreactor). The $\mathrm{C}_{i}$ values of the different system ranges from $1.17 \times 10^{-4}$ to $1.51 \times 10^{-4}$ moles/L/day. Both the $\mathrm{pH}$ of the BRSP and NPK media at $10 \mathrm{~g} / \mathrm{L}$ and $30 \mathrm{~g} / \mathrm{L}$ loading of $\mathrm{NaHCO}_{3}$ increased through time. The result shows that $A$. falcatus has a potential in BICCAPS utilization.
\end{abstract}

\section{Introduction}

The increasing level of carbon dioxide $\left(\mathrm{CO}_{2}\right)$ in the atmosphere had caused severe impact in global temperature. The mean $\mathrm{CO}_{2}$ concentration in the atmosphere had passed the $400 \mathrm{ppm}$ mark which is beyond the safety limit of $350 \mathrm{ppm}$ [1]. The major culprit for in the increase in $\mathrm{CO}_{2}$ in the atmosphere is the utilization of fossil fuel for energy generation and trasnportation. Several strategies is been used to reduce or prevent further release of $\mathrm{CO}_{2}$ such as improvement in the technology, energy conservation, utilization of renewable technology and $\mathrm{CO}_{2}$ sequestration [2].

Carbon Capture and Sequestration (CCS) system is the most viable techniques to be applied for exisiting industrial plants. In CCS system, the $\mathrm{CO}_{2}$ gas is captured in an amine-based or carbonate-based adsorbents and stored in a vessel as compressed gas and transported to a place where it could have negligible effect on the environment [3]. Still, these technologies are energy intensive because of the thermal treatment required to regenerate the absorbents rendering it to be expensive [4]. Alternative CCS technology utilized alkaline solutions (e.g. $\mathrm{NaOH}$ ) and microalgae in photobioreactor [5-6].

The popularity of microalgae as CCS is due to high growth rate and capture carbon capability on top of that it could be used as a potential fuels source. One of the several microalgae that has been evalauted as biofuel feedstock is Ankistrodemus falcatus [7-9]. Although, study for it as potential for CCS were limited. One study reported that $A$. falcatus grew in a specialized PHM medium able to havecarbon removal rate of $20 \%$ utilizing a $2 \% \mathrm{CO}_{2}$ feed gas stream [10]. A. falcatus has reported to contain a lipid of more than $35 \%$, optimal growth length of $0.20 \mu \mathrm{m}$ and a biomass productivity of $7.9 \mathrm{mg} / \mathrm{L}$-day in a BG-11 medium [8]. Also, it was capable to produce a lipid yield of $67.2 \%$, but it had already undergone a morphology change. With another study, it was known that nitrogen, phosphorus and iron nutrient has a significantly effect in lipid productivity and can obtained biofuel conversion rate as high as $91 \%$ [7].

Bicarbonate-based Integrated Carbon Capture and Algae Production System (BICCAPS) is an improvement of CCS system where both chemical and biological systems together is being utlized [4]. The technology captures $\mathrm{CO}_{2}$ in the form of bicarbonate as alkali solution and utilizes it as carbon source for microalgae. The microalgae should be able to withstand a highly alkaliphilic environment for this system to be viable thus limit the study to some cyanobacteria species.

Liu et al. conducted a study that utilized Chlorella $s p$. and Scenedesmus obliquus sp. in a continuous system using bicarbonate-based media and observed that the microalgae was able to grow at a rate of $0.41 \mathrm{~g}$ (dry weight) per gram of $\mathrm{HCO}_{3}{ }^{-}$[11]. In another study, it was determined that Euthalothece ZM001 species has potential for BICCAPS system due to its biomass productivity of $1.21 \mathrm{~g} / \mathrm{L}$-day while the Spirulina species

* Corresponding author: arnel.beltran@dlsu.edu.ph 
has low potential due to its low biomass productivity of $0.15-0.43 \mathrm{~g} / \mathrm{L}-$ day [4]. One study found out that the used of sodium bicarbonate in culture media is advantageous because of its capability to increase microalgae cells and the amount of lipids in Tetraselmis suecica and Nannochloropsis salina [12]. However, no studies were reported in utilizing bicarbonate solutions in the growth of falcatus.

Thus, this study attempted to evaluate the utilization of bicarbonates for the growth of A. falcatus. The solution $\mathrm{pH}$, algal biomass productivity and $\mathrm{CO}_{2}$ utilization as inorganic carbon conversion $\left(\mathrm{C}_{\mathrm{i}}\right)$ were determined at different salt loading concentration and type of culture media.

\section{Experimental}

\subsection{Materials}

The following reagents and materials were used in the study: sodium bicarbonate $\left(\mathrm{NaHCO}_{3}\right.$, Himedia, 99.5\%) and filter membrane (Pall, $0.45 \mu \mathrm{m}$ ) purchased from Yana Chemodities Inc., $\mathrm{CO}_{2}$ gas (Technical grade) obtained from Linde Philippines. Analytical grade of barium chloride $(\mathrm{BaCl})$, potassium hydrogen phthalate, sodium hydroxide $(\mathrm{NaOH})$ pellets, hydrochloric acid ( $\mathrm{HCl}$, Univar, 36\%), phenolphthalein indicator and bromocresol green indicator were procured from Crimson Scientific \& Laboratory Supply.

\subsection{Microalgal strain, culture media and cultivation}

Southeast Asian Fisheries Development Center (SEAFDEC) provided the alkaliphilic freshwater microalgae Ankistrodesmus falcatus maintained in NPK (14-14-14) commercial fertilizer medium and the BRSP medium (formulation from SEAFDEC) as stock culture. For culture media preparation the following formulation were followed: for BRSP media, a ratio of 1:9 of BRSP concentrated solution to distilled water and for NPK media, a $0.1 \mathrm{~g} \mathrm{~N}_{14} \mathrm{P}_{14} \mathrm{~K}_{14}$ fertilizer per liter of distilled water.

Microalgae cultivation is done in a $12 \mathrm{~h}$ light $/ 12 \mathrm{~h}$ dark cycle utilizing a light source with intensity of approximately 1 Klux. All runs were done at normal ambient temperature conditions in a 4-L PET bottle photobioreactors at a working volume of $3 \mathrm{~L}$.

A. falcatus is cultivated in an open system as air pumps were used to deliver $\mathrm{CO}_{2}$ from air. The growth curves of obtained from the experiment were used as standard for biomass production.

\subsection{Algal production}

Batches of 3.0 L NPK and BRSP media with $10 \mathrm{~g} / \mathrm{L}$ and $30 \mathrm{~g} / \mathrm{L}$ loading of $\mathrm{NaHCO}_{3}$ were prepared and inoculated with 1:9 algal ratios to culture media. The microalgae were cultured in the solution for 21 days in a $12 \mathrm{~h}$ light/12h dark cycle with a light intensity of approximately 1 Klux at normal ambient temperature conditions at a closed system. Optical density and $\mathrm{pH}$ readings were measured on a regular basis.

\subsection{Analysis}

The microalgae growth curves in NPK and BRSP media were determined using UV-vis spectrophotometer (Shimadzu UV-170) at a wavelength of $725 \mathrm{~nm}$ (optical density, OD) and dry biomass weight (DBW) for 30 days cultivation. DBW were determined by obtaining the mass of the biomass from the sample by filtering it with 0.45 micron filter and dried at $100^{\circ} \mathrm{C}$ for $3 \mathrm{hrs}$.

Double-indicator titration method is used to obtain the bicarbonate and carbonate content of the samples with $\mathrm{HCl}$ solution as standard. Volumes of the standardized $\mathrm{HCl}$ solution were determined in the titration of $10.0 \mathrm{~mL}$ filtered sample (with 0.45 micron filter) until the phenolphthalein endpoint $\left(\mathrm{V}_{1 \mathrm{HCl}}\right.$, light pink, carbonate content) and the bromocresol green endpoint $\left(\mathrm{V}_{2 \mathrm{HCl}}\right.$, faint yellow, bicarbonate content). The carbonate and bicarbonate concentration were determined using (1) and (2), respectively.

$$
\begin{aligned}
& C_{\mathrm{CO}_{3}^{2-}}=C_{\mathrm{HCl}} V_{1 \mathrm{HCl}} \times 100 \\
& C_{\mathrm{HCO}_{3}^{-}}=C_{\mathrm{HCl}}\left[V_{2 \mathrm{HCl}}-V_{1 \mathrm{HCl}}\right] \times 100
\end{aligned}
$$

The presence of dissolve $\mathrm{CO}_{2}$ gas in the samples was obtained using precipitation-titration method. Standardized $\mathrm{NaOH}$ solution $(10 \mathrm{~mL})$ was added to 10 $\mathrm{mL}$ sample which convert the dissolve $\mathrm{CO}_{2}$ in the solution to $\mathrm{CO}_{3}{ }^{2-}$. The carbonate is precipitated as barium carbonate $\left(\mathrm{BaCO}_{3}\right)$ by adding an excess $\mathrm{BaCl}$ solution in the prepared sample. Excess hydroxide is titrated with standardized $\mathrm{HCl}$ solution to phenolphthalein endpoint $\left(\mathrm{V}_{3 \mathrm{HCl}}\right)$. Dissolve $\mathrm{CO}_{2}$ gas concentration in the solution was obtained using (3).

$$
C_{\mathrm{CO}_{2}}=\left\lfloor C_{\mathrm{HCl}} V_{3 \mathrm{HCl}}-C_{\mathrm{HCO}_{3}^{-}} V_{\text {sample }}\right\rfloor \times 50
$$

\section{Results and Discussion}

The growth curve of A. falcatus for both BRSP and NPK media for 30 days with air sparging is shown in Fig. 1. The results shows that the stationary phase is evident in NPK media at around day 22 but not yet visible in BRSP media during the cultivation period. Fig. 2 show the the linearized plot of a first order growth rate of $A$. falcatus for both BRSP and NPK media using (4).

$$
\ln \mathrm{DBW}=u_{\max } t+\ln \mathrm{DBW}_{0}
$$

The slope of the line is the maximum specific growth rate $\left(\mathrm{u}_{\max }\right)$ of the algal growth. It was determined that the $\mathrm{u}_{\max }$ for $A$. falcatus are 0.0515 /day and 0.0349 /day for BRSP media and NPK media, respectively. These results indicates that BRSP is the more favourable growth media for A. falcatus. This could be due to the present of essential nutrient in BRSP for algal metabolism such as Biotin, Thiamine, and Vitamin $\mathrm{B}_{12}$ [13]. A. falcatus biomass productivity (BP) is calculated using (5), where $\mathrm{DBW}_{0}$ and $\mathrm{DBW}_{\mathrm{f}}$ are initial and final DBW of $A$. falcatus and $\mathrm{t}$ is the time of cultivation. It was determined that the BP for BRSP media is 5.09 $\mathrm{mg} / \mathrm{L}$-day while $3.59 \mathrm{mg} / \mathrm{L}$-day for NPK media. 


$$
B P=\frac{D B W_{f}-D B W_{0}}{t}
$$

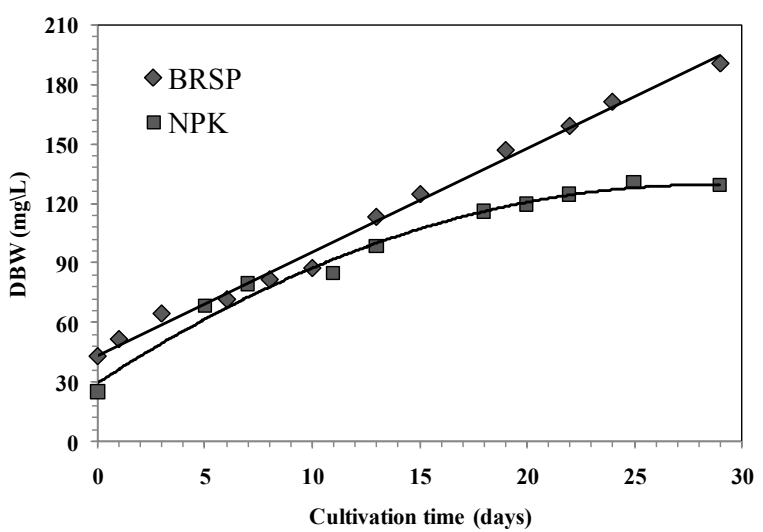

Fig 1. Growth curve of $A$. falcatus in BRSP and NPK culture media.

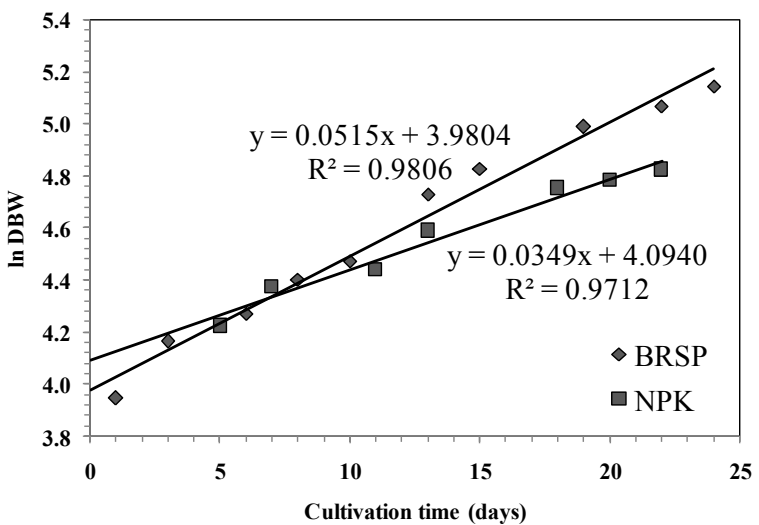

Fig 2. Linearized first order growth rate of $A$. falcatus in BRSP and NPK culture media.

The algal growth and the media physico-chemical properties for bicarbonate-based media at $10 \mathrm{~g} / \mathrm{L}$ loading were observed for 21 days in a closed system and the results are shown in Fig. 3 to Fig. 7.

From Fig. 3, it could be observe that even though there is no purging of air, the alga was able to grow because of the presence of bicarbonate ions as carbon source. It can be seen that both the growth in BRSP and NPK are still increasing linearly without any trace of stationary phase. Also, the growth at $10 \mathrm{~g} / \mathrm{L}$ loading of $\mathrm{NaHCO}_{3}$ (Fig. 3a) is much higher than $30 \mathrm{~g} / \mathrm{L}$ loading (Fig. 3b). This is attributed to higher concentration of $\mathrm{Na}^{+}$in the media which is determental to the growth of the algae. Moreover, higher growth is observed for BRSP media with bicarbonate salt in closed system.

Biomass productivities were determined to be $3.554 \mathrm{mg} / \mathrm{L}$-day and $0.954 \mathrm{mg} / \mathrm{L}$-day for BRSP media at $10 \mathrm{~g} / \mathrm{L}$ and $30 \mathrm{~g} / \mathrm{L}$ laoding, respectively. While for NPK media, BP values are $1.801 \mathrm{mg} / \mathrm{L}$-day and $0.936 \mathrm{mg} / \mathrm{L}-$ day for $10 \mathrm{~g} / \mathrm{L}$ and $30 \mathrm{~g} / \mathrm{L}$ laoding, respectively.

Fig. 4 provide the linearized plot of a first order growth rate of $A$. falcatus for bicarbonate-based media in closed system. The $u_{\max }$ observed at $10 \mathrm{~g} / \mathrm{L}$ loading are 0.0604 /day and 0.0428 /day for BRSP media and NPK media, respectively. On the otherhand, $u_{\max }$ at $30 \mathrm{~g} / \mathrm{L}$ loading are 0.0207 /day and 0.0286 /day for BRSP media and NPK media, respectively.
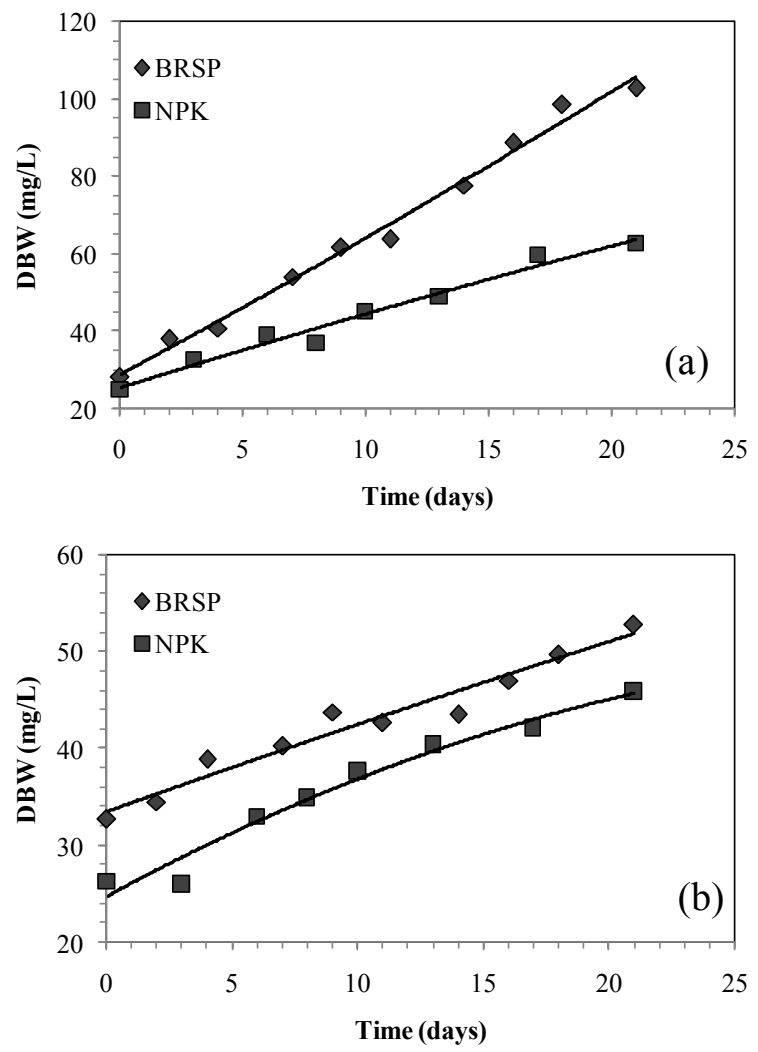

Fig 3. Growth curve of $A$. falcatus in closed $\mathrm{BRSP}-\mathrm{NaHCO}_{3}$ solution and closed NPK- $-\mathrm{NaHCO}_{3}$ solution media at (a) $10 \mathrm{~g} / \mathrm{L}$ and (b) $30 \mathrm{~g} / \mathrm{L}$ loading.
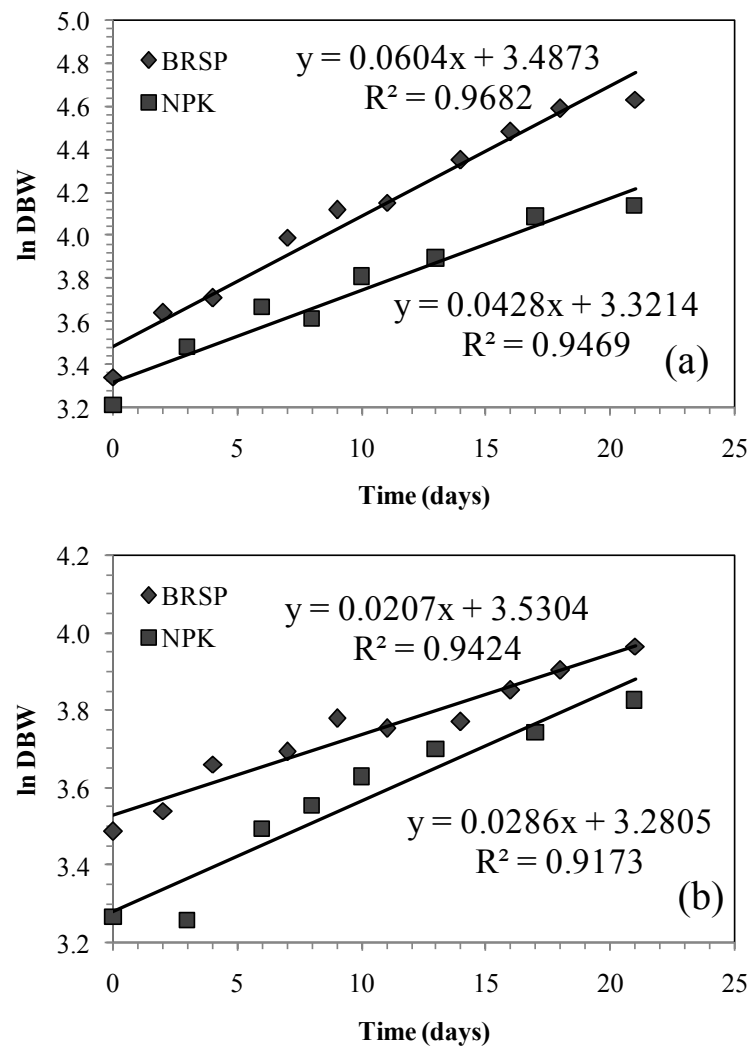

Fig 4. Linearized first order growth rate of $A$. falcatus in closed BRSP$\mathrm{NaHCO}_{3}$ solution and closed NPK-NaHCO 3 solution media at (a) 10 $\mathrm{g} / \mathrm{L}$ and (b) $30 \mathrm{~g} / \mathrm{L}$ loading.. 
At $10 \mathrm{~g} / \mathrm{L}$ loading, for the bicarbonatete-based BRSP media, the $\mathrm{u}_{\max }$ was higher by $17 \%$ that the airated BRSP media while for the bicarbonatete-based NPK media the $u_{\max }$ was higher by $23 \%$. While at $30 \mathrm{~g} / \mathrm{L}$ loading, the value was reduced by $60 \%$ compared to the aerated BRSP media but only $18 \%$ reduction is observed for bicarbonatete-based NPK media compared to the aerated one. The higher value for $10 \mathrm{~g} / \mathrm{L}$ laoding could be due to low agitation observed in the closed system that the aerated system while the lowvalue for $30 \mathrm{~g} / \mathrm{L}$ loading is caused by $\mathrm{Na}^{+}$inhibition.

The $\mathrm{pH}$ for both closed systems increases as cultivation time progressed as shown in Fig. 5. The $\mathrm{pH}$ increased from 8.54 to 9.07 for the BRSP media while for the NPK, the increased was from 8.64 to 9.06 at 10 $\mathrm{g} / \mathrm{L}$ loading. At $30 \mathrm{~g} / \mathrm{L}$ laoding, $\mathrm{pH}$ increased from 8.51 to 8.80 in BRSP media while in NPK media the increased was from 8.64 to 8.99 .
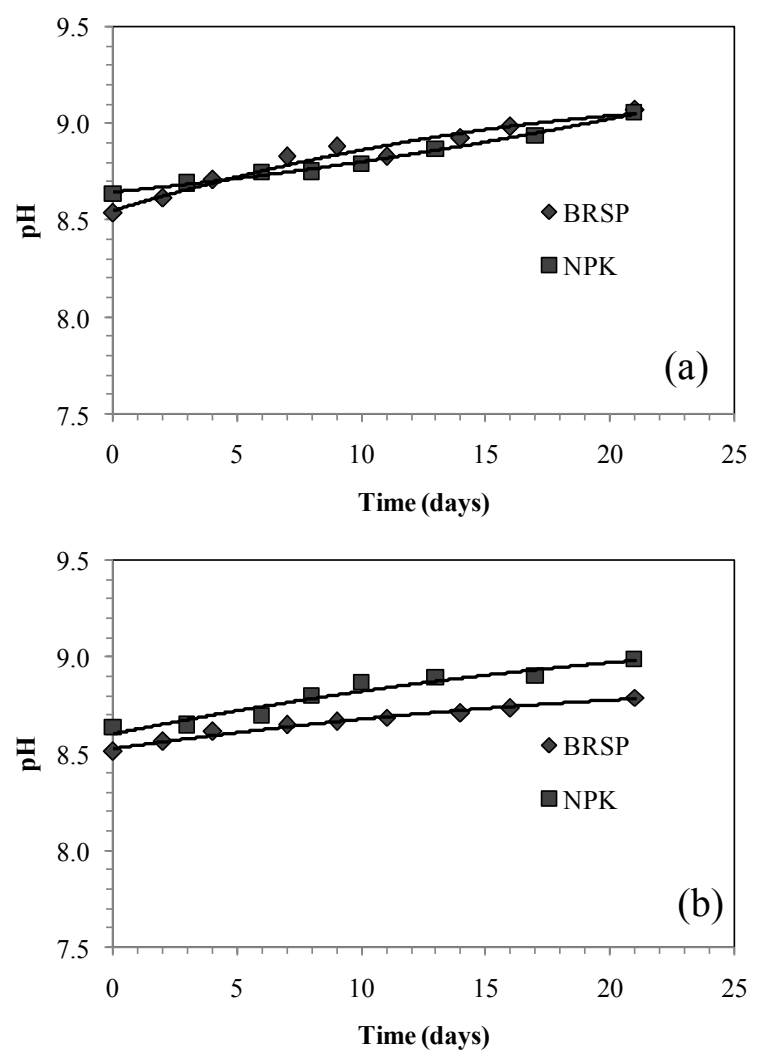

Fig 5. $\mathrm{pH}$ profile in closed BRSP-NaHCO 3 solution and closed NPK$\mathrm{NaHCO}_{3}$ solution media during growth of $A$. falcatus.

Fig. 6 and 7 show the $\mathrm{HCO}_{3}^{-}$and $\mathrm{CO}_{3}{ }^{2-}$ concentration of the closed system. As the concentration of $\mathrm{HCO}_{3}{ }^{-}$in both media goes down it can be observed the $\mathrm{CO}_{3}{ }^{2-}$ concentration have increased. This indicates that the microalgae's growth is due to the uilization of the bicarbonate and convert it to carbonate in the system by the microorganism. Then production of carbonate then thends the $\mathrm{pH}$ of the system to goes up.
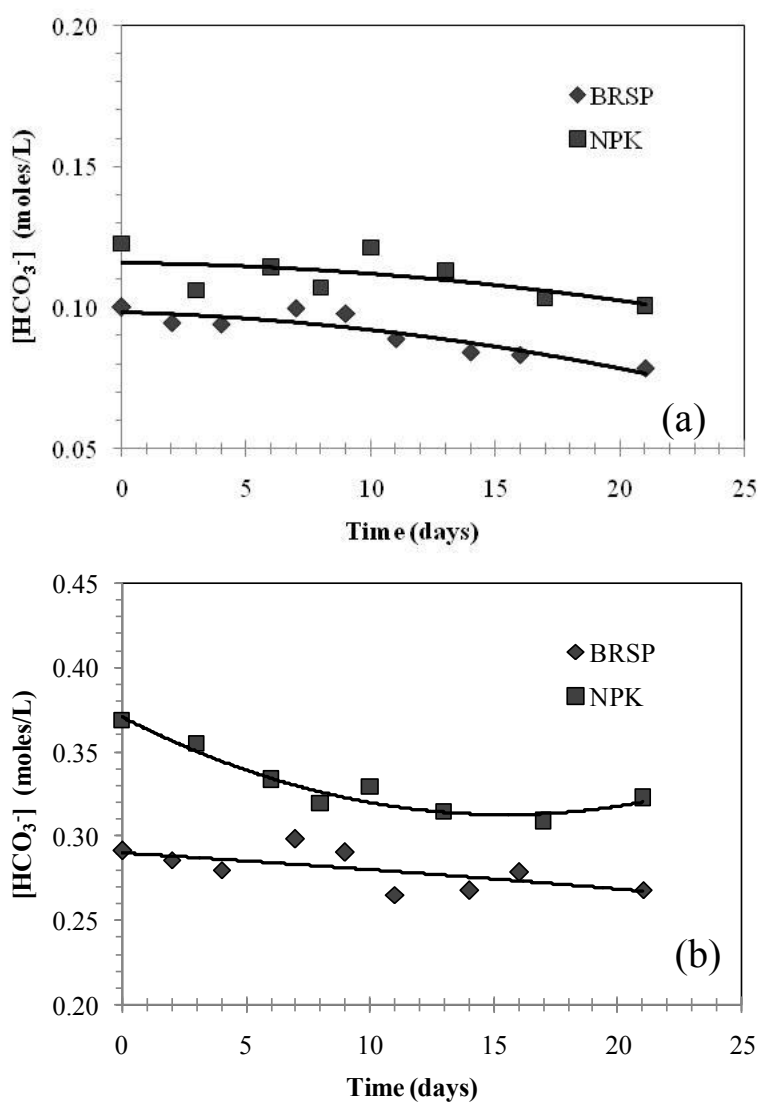

Fig 6. Bicarbonate concentration of closed $\mathrm{BRSP}-\mathrm{NaHCO}_{3}$ solution and closed NPK-NaHCO 3 solution media during growth of $A$. falcatus.
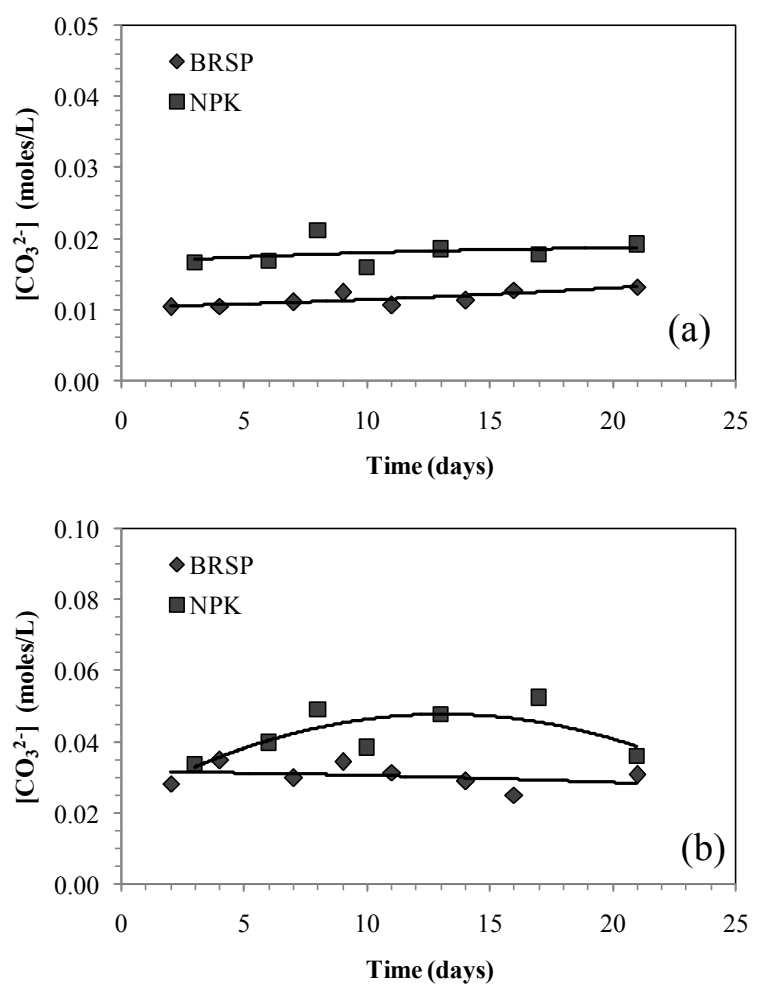

Fig 7. Carbonate concentration of closed $\mathrm{BRSP}-\mathrm{NaHCO}_{3}$ solution and closed NPK-NaHCO 3 solution media during growth of $A$. falcatus.

Inorganic Carbon $\left(\mathrm{C}_{\mathrm{i}}\right)$ conversion was defined as the equivalent amount of $\mathrm{CO}_{2}$ that is converted to biomass per culture volume per time (moles/L-day) and 
was calculated using (6) where $\left[\mathrm{CO}_{3}{ }^{2-}\right]_{\mathrm{f}}$ and $\left[\mathrm{CO}_{3}{ }^{2-}\right]_{\mathrm{i}}$ are the initial and final concentration of $\mathrm{CO}_{3}{ }^{2-}$ in the media, $\left[\mathrm{CO}_{2}\right]_{\mathrm{f}}$ and $\left[\mathrm{CO}_{2}\right]_{\mathrm{i}}$ are the initial and final concentration of $\mathrm{CO}_{2}$ in the media and $\mathrm{t}$ is the time of cultivation. For the bicarbonate-based system, this is the amount of bicarbonate converted to biomass.

$$
C_{i}=\frac{\left(\left[\mathrm{CO}_{3}^{2-}\right]_{f}-\left[\mathrm{CO}_{3}^{2-}\right]_{i}\right)+\left(\left[\mathrm{CO}_{2}\right]_{i}-\left[\mathrm{CO}_{2}\right]_{f}\right)}{t}
$$

The calculated $\mathrm{C}_{\mathrm{i}}$ for BRSP media at $10 \mathrm{~g} / \mathrm{L}$ loading was $1.508 \times 10^{-4} \mathrm{moles} / \mathrm{L}$-day while $1.260 \times 10^{-4} \mathrm{moles} / \mathrm{L}$-day is determined for the NPK media. At $30 \mathrm{~g} / \mathrm{L}$ laoding, $\mathrm{Ci}$ value calculated were $1.432 \times 10^{-4}$ moles/L-day and $1.166 \times 10^{-4}$ moles/L-day for BRSP and NPK media, respectively.

\section{Conclusion}

The utilization of bicarbonates in solution media for the growth of Ankistrodesmus falcatus was investigated. It was observed that growth of A. falcatus is higher in BRSP media than in NPK due to some essential nutrients necessary for algal growth. On the otherhand, bicarbonates laoding at $10 \mathrm{~g} / \mathrm{L}$ show higher growth than the $30 \mathrm{~g} / \mathrm{L}$ loading attrbitued to the growth inhibition of $\mathrm{Na}^{+}$. The $\mathrm{pH}$ of the solution media increases as the bicarbonates is utilized and converted to carbonate ions. The result shows that $A$. falcatus can be utilized to in BICCAPS process.

\section{References}

1. CO2.Earth. Available at: https://www.co2.earth [Accessed September 7, 2017]

2. B.P. Spigarelli, K. Kawatra, J. CO2 Util. 1, 69 (2013)

3. J. Gibbins, H. Chalmers, Energy Pol. 36, 4317 (2008)

4. Z. Chi, Y. Xie, F. Elloy, Y. Zheng, Y. Hu, S. Chen, Bioresour. Technol. 133, 513 (2013)

5. M. Mahmoudkhani, D. Keith, Int. J. Greenh. Gas Control. 3, 376 (2009)

6. H. Znad, G. Naderi, H.M. Ang, M.O. Tade, Book Chapter In: Z. Nawaz, eds. Advances in Chemical Engineering (2012)

7. P. Singh, A. Guldhe, S. Kumari, I. Rawat, F. Bux, Biochem. Eng. J. 94, 22 (2015)

8. B. George, I. Pancha, C. Desai, K. Chokshi, C. Paliwal, T. Ghosh, S. Mishra, Bioresource Technol. 171, 367 (2014)

9. T. Jayanta, K. Chandra, G. Chandra, Int. Res. J. Biol. Sci. 61, 27 (2012)

10. A. Rinanti, E. Kardena, D. Astuti, K. Dewi, Asian Trans. Sci. \& Tech. 3, 1 (2013)

11. G. Liu, L. Qiao, H. Zhang, , S. Xia, D. Zhao, Enrgy. Proced. 61, 361 (2014)

12. D. White, A. Pagarette, P. Rooks, S. Ali, J. Appl. Phycol. 25, 153 (2013)
13. L. Provasoli, A. F. Carlucci, in: W. D. P. Stewart eds. Algal physiology and biochemistry (1974) 